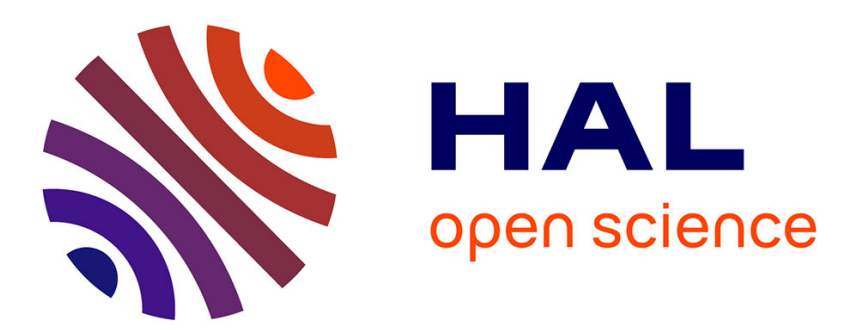

\title{
DIFFUSION OF IMPURITIES IN IONIC CRYSTALS AS STUDIED BY NUCLEAR MAGNETIC RESONANCE TECHNIQUES
}

\author{
H. Richtering, K. Becker, H. Hamann
}

\section{- To cite this version:}

H. Richtering, K. Becker, H. Hamann. DIFFUSION OF IMPURITIES IN IONIC CRYSTALS AS STUDIED BY NUCLEAR MAGNETIC RESONANCE TECHNIQUES. Journal de Physique Colloques, 1976, 37 (C7), pp.C7-373-C7-378. 10.1051/jphyscol:1976785 . jpa-00216945

HAL Id: jpa-00216945

https://hal.science/jpa-00216945

Submitted on 1 Jan 1976

HAL is a multi-disciplinary open access archive for the deposit and dissemination of scientific research documents, whether they are published or not. The documents may come from teaching and research institutions in France or abroad, or from public or private research centers.
L'archive ouverte pluridisciplinaire HAL, est destinée au dépôt et à la diffusion de documents scientifiques de niveau recherche, publiés ou non, émanant des établissements d'enseignement et de recherche français ou étrangers, des laboratoires publics ou privés. 


\title{
DIFFUSION OF IMPURITIES IN IONIC CRYSTALS AS STUDIED BY NUCLEAR MAGNETIC RESONANCE TECHNIQUES
}

\author{
H. RICHTERING, K. D. BECKER and H. HAMANN \\ Abteilung Chemie, Ruhr-Universität \\ D-4630 Bochum FRG
}

\begin{abstract}
Résumé. - La méthode de l'investigation de la diffusion des défauts atomiques dans les cristaux ioniques cubiques par mesure de la relaxation nucléaire magnétique est très brièvement décrite. Des exemples sont donnés pour la relaxation longitudinale et transversale des noyaux ${ }^{81} \mathrm{Br}$ et ${ }^{35} \mathrm{Cl}$ dans le $\mathrm{LiBr}, \mathrm{TlBr}, \mathrm{AgCl}$ et $\mathrm{AgBr}$.

Les coefficients d'autodiffusion obtenus pour $\mathrm{Cu}^{+}$et $\mathrm{Ag}^{+}$dans $\mathrm{LiBr}$ aux températures au-dessus de $350^{\circ} \mathrm{C}$ sont

$$
D\left(\mathrm{Cu}^{+}\right)=8 \exp (-1,0 \mathrm{eV} / k T) ; D\left(\mathrm{Ag}^{+}\right)=1 \exp (-1,0 \mathrm{eV} / k T) \mathrm{cm}^{2} \mathrm{~s}^{-1} .
$$

Dans $\mathrm{TlBr}$ à $400{ }^{\circ} \mathrm{C}$, les impuretés $\mathrm{K}^{+}, \mathrm{Rb}^{+}$et $\mathrm{Cs}^{+}$ont la même fréquence moyenne de saut. Cette fréquence est à peu près 3 fois plus grande que celle de $\mathrm{Tl}^{+}$est 3 fois plus petite que celle de $\mathrm{Br}^{-}$. A $300{ }^{\circ} \mathrm{C} \mathrm{Ag}{ }^{+}$diffuse même 10 fois plus vite que $\mathrm{Br}^{-}$.

Dans $\mathrm{AgCl}$ avec un dopage de $\mathrm{CuCl}$ la fréquence de formation d'un complexe de défaut $\left(\mathrm{Cu}_{\mathrm{i}} \mathrm{V}_{\mathrm{Ag}}^{\prime}\right)$ est observée. Les sauts atomiques combinés avec la formation et la recombination de ce complexe ne contribuent pas sensiblement à la diffusion de traceur du cuivre.

Dans $\mathrm{AgBr}$ avec un dopage de $\mathrm{CuBr}$ et traité avec $\mathrm{Br}_{2}$ les mesures de relaxation montrent que des ions $\mathrm{Cu}^{2+}$ sont formés. Les fréquences de saut $\mathrm{du} \mathrm{Cu}^{2+}$ et $\mathrm{du} \mathrm{Cu}^{+}$peuvent être déterminées
\end{abstract} l'une à côté de l'autre au voisinage de $200^{\circ} \mathrm{C}$.

\begin{abstract}
The method to investigate the diffusion of atomic defects in cubic ionic crystals by measurements of $\mathrm{nmr}$ relaxation rates is described very briefly. Examples are given for longitudinal and transversal relaxation of $81 \mathrm{Br}-$ and ${ }^{35} \mathrm{Cl}-$ nuclei in $\mathrm{LiBr}, \mathrm{TlBr}, \mathrm{AgCl}$ and $\mathrm{AgBr}$.

Selfdiffusion coefficients obtained for $\mathrm{Cu}^{+}$and $\mathrm{Ag}^{+}$in $\mathrm{LiBr}$ at temperatures above $350^{\circ} \mathrm{C}$ are $D\left(\mathrm{Cu}^{+}\right)=8 \exp (-1.0 \mathrm{eV} / k T) ; D\left(\mathrm{Ag}^{+}\right)=1 \exp (-1.0 \mathrm{eV} / k T) \mathrm{cm}^{2} \mathrm{~s}^{-1}$.

In $\mathrm{TlBr}$ at $400{ }^{\circ} \mathrm{C}$ the foreign ions $\mathrm{K}^{+}, \mathrm{Rb}^{+}$and $\mathrm{Cs}^{+}$have the same mean jump frequency. This frequency is about 3 times larger than that of $\mathrm{Tl}^{+}$and 3 times smaller than that of $\mathrm{Br}^{-}$. $\mathrm{Ag}^{+}$diffuses at $300^{\circ} \mathrm{C}, 10$ times faster than even $\mathrm{Br}^{-}$.

In $\mathrm{AgCl}$ doped with $\mathrm{CuCl}$ the frequency of formation of a defect pair $\left(\mathrm{Cu}_{\mathrm{i}}^{\prime} \mathrm{V}_{\mathrm{Ag}}^{\prime}\right)$ is observed. The jump processes connected with formation and recombination of this pair do not contribute considerably to $\mathrm{Cu}$ tracer diffusion.

In $\mathrm{AgBr}$ doped with $\mathrm{CuBr}$ and treated with bromine the relaxation measurements show that $\mathrm{Cu}^{2+}$ - ions are formed. The jump frequency of $\mathrm{Cu}^{2+}$ can be determined besides that of $\mathrm{Cu}^{+}$at temperatures about $200{ }^{\circ} \mathrm{C}$.
\end{abstract}

1. Introduction. - The diffusion of atomic defects in cubic crystals can be studied by nuclear magnetic resonance techniques provided the nuclei of a main constituent have an electric quadrupole moment. The most important quantity in this context is the correlation time $\tau$ of the relative diffusive motion between the defects (D) and the relevant main constituent (A) for which the nmr-signals are recorded. Pronounced peaks in nuclear magnetic relaxation rates can be observed in that temperature region, in which the reciprocal of the correlation time $\tau$ is of the same magnitude as the nuclear Larmor-frequency $\omega_{\mathrm{L}}=2 \pi v_{\mathrm{L}}$ in the applied magnetic field. Responsible for this type of relaxation is the interaction between the quadrupole moments of species $\mathrm{A}$ and the electric field gradients produced by the defects D. This interaction is fluctuating in time and intensity because of the relative diffusive motion and thereby leads to nmr-relaxation.

A theory connecting nmr quadrupole relaxation rates with jump frequencies of defects in solids has been given by Cohen and Reif as early as $1954[1,2,3]$. The formulae which are used in this paper are given in section 2. Hints to their derivation can be found in [4].

Various authors have studied the diffusion of vacancies in doped ionic crystals by this method $[5,6(\mathrm{LiBr}) ; 7(\mathrm{NaF}) ; 8,9(\mathrm{NaCl}) ; 2,10(\mathrm{AgBr})]$. Our main interest has been the diffusion of foreign ions $[11,12]$. We have also checked the theory for longitudinal and transversal relaxation in respect to the dependence on Larmor-frequency and on concentration of foreign ions [4]. Of special importance is the comparison of diffusion coefficients obtained by the 
nmr-method with tracer results. The agreement in some cases is excellent. There are, however, cases, in which large deviations occur (see section 5). The purpose of this paper is to give some examples which demonstrate the possibilities of the method.

2. Basic formulae and experimental procedure. For the correlation time $\tau$ of the relative diffusive motion between the defects $D$ and the nuclei of species $\mathrm{A}$ the following relation holds

$$
\frac{1}{\tau}=v(\mathrm{D})+v(\mathrm{~A})
$$

$v(D)$ and $v(A)$ are mean jump frequencies of $\mathrm{D}$ and $\mathrm{A}$ respectively. In most cases which have been investigated, $v(\mathrm{~A})$ is much smaller than $v(\mathrm{D})$ and can therefore be neglected.

For nuclei A with spin quantum number $I=3 / 2$ Hubbard [13] has derived the following result for quadrupole relaxation of nuclear magnetization in the direction of the external field (longitudinal relaxation; $M_{z}^{0}:$ magnetization in thermal equilibrium)

$$
\begin{aligned}
M_{z}^{0}-M_{z}(t)=2 M_{z}^{0} & \left\{\frac{1}{5} \exp \left(-2\left(w_{1}+w_{\mathrm{g}}\right) t\right)+\right. \\
& \left.+\frac{4}{5} \exp \left(-2\left(w_{2}+w_{\mathrm{g}}\right) t\right)\right\}
\end{aligned}
$$

$w_{1}$ and $w_{2}$ contain the contribution of diffusion to quadrupole relaxation, $w_{\mathrm{g}}$ represents the contribution of lattice vibrations. $w_{\mathrm{g}}$ can be determined seperately by measurements with pure samples.

Experimentally $M_{z}(t)$ was followed by standard pulse techniques with a Bruker nmr-spectrometer (BKR 321 s). In addition to an electromagnet with iron core a kryomagnet has been used which allowed magnetic fields up to $6.3 \times 10^{4} \mathrm{G}$. Experimental details are described elsewhere $[4,14]$. From measurements on a doped and the corresponding pure sample $w_{1}$ and $w_{2}$ can be obtained as function of temperature $T$. Since the determination of $w_{2}$ always was more reliable, all the results for longitudinal relaxation are plotted as $w_{2}(T)$.

With a simple exponential correlation function for the diffusive motion, $w_{1}$ and $w_{2}$ are related to $\tau$ in the following manner

$$
\begin{aligned}
& w_{1}=\text { Const. } \frac{x_{\mathrm{d}} \cdot \tau}{1+\omega_{\mathrm{L}}^{2} \tau^{2}} \\
& w_{2}=\text { Const. } \frac{x_{\mathrm{d}} \cdot \tau}{1+4 \omega_{\mathrm{L}}^{2} \tau^{2}}
\end{aligned}
$$

$\omega_{\mathrm{L}}=2 \pi v_{\mathrm{L}}$ is the Larmor frequency, $x_{\mathrm{d}}$ is the mole fraction of defects produced by doping. It is assumed that only one type of defect is responsible for relaxation in a certain temperature range. For a given concentration $x_{d}$ the maximum of $w_{2}$ as function of temperature shows up for

$$
\begin{aligned}
\frac{1}{\tau^{*}} & =2 \omega_{\mathrm{L}} \\
w_{2}^{*} & \sim \frac{x_{\mathrm{d}}}{\omega_{\mathrm{L}}} .
\end{aligned}
$$

(All quantities at the relaxation maximum are marked by an asterisk in this article.) By means of (3) and (4) the correlation time $\tau$ can be calculated as function of temperature from the experimentally determined $w_{2}(T)$.

For relaxation of nuclear magnetization perpendicular to the external field (transversal relaxation) Hubbards result is $[13,4]$ :

$$
M_{x}(t)=0.4 M_{z}^{0} \exp \left(-\left(w_{1}+w_{2}\right) t\right) .
$$

This relation holds under the assumption that only the two central Zeeman levels contribute to the detected signal. This assumption is justified for the nuclei ${ }^{81} \mathbf{B r}$ and ${ }^{35} \mathrm{Cl}$, for which results are given in this article. The reason is that static quadrupole interactions in the samples shift the outer levels. Their contribution to the signal is therefore wiped out $[2,15]$.

By conventional cw-detection of the nmr absorption signal in a wide-line spectrometer (Varian, DP 60) the Fourier transform of $M_{x}(t)$ is obtained. The contribution to the linewidth by quadrupole relaxation is given by

$$
\gamma \cdot \Delta H_{\mathrm{q}}=1.15\left(w_{1}+w_{2}\right)
$$

$\gamma$ is the gyromagnetic ratio, $\Delta H_{\mathrm{q}}$ is the linewidth between the inflection points of the absorption signal. From $\Delta H$ as determined from the registration curve, a contribution of the static dipolar linewidth must be subtracted to get $\Delta H_{\mathrm{q}}$ as function of temperature. Measurements with the pure sample again serve for this purpose. At the linewidth-maximum which corresponds to the maximum in transversal relaxation, the following relations are valid [4]

$$
\begin{aligned}
& \frac{1}{\tau^{*}}=1.23 \omega_{\mathrm{L}} \\
& \gamma \Delta H_{\mathrm{q}}^{*} \sim \frac{x_{\mathrm{d}}}{\omega_{\mathrm{L}}}
\end{aligned}
$$

In respect to simplifications which were made in the derivation of the formulae above, some comments seem to be in order:

1) In equation (1) each of the two jump frequencies should be multiplied by a correlation factor $f_{i}^{\mathrm{nmr}}$. Such factors originate from the influence of the correlation between successive jumps on the nmr-measurements [16, 17]. They are smaller than one but of the order of one. For jumps on nearest neighbour sites in a face centered cubic lattice for example $f_{\mathrm{A}}^{\mathrm{nmr}} \approx 0.7$ [17]. The correla- 
tion factor $f_{\mathrm{A}}^{\mathrm{tr}}$ connecting tracer diffusion and ionic conductivity in the same case is 0.78 [see e. g. 18]. $f^{\mathrm{nmr}}$ always seems to be somewhat smaller than $f^{\text {tr }}$.

2) A simple exponential is not the correct correlation function for lattice diffusion with random walk on a specified lattice. An improvement has been given by Torrey [19].

More recent work by Wolf $[17,20]$ includes both factors. The calculations for any specified jump mechanism on a given lattice are rather complex. In most of our examples, however, the diffusion mechanism is unknown and different jump processes for the same defect may contribute to relaxation. We therefore decided to use a simple exponential correlation function together with $f^{\mathrm{nmr}}=1$ as standard procedure in calculating jump frequencies from our measurements. This may be justified because we are often interested in comparison between various foreign ions and in large differences in the jump frequencies. In addition, an example given by Wolf shows that there is a chance of cancellation of errors from the two simplifications.

3. Diffusion of $\mathrm{Cu}^{+}$and $\mathrm{Ag}^{+}$in $\mathrm{LiBr}$. - For the ${ }^{81} \mathrm{Br}$ resonance we have measured both the linewidth and the longitudinal relaxation up to the melting point $\left(550^{\circ} \mathrm{C}\right)$. Results for $\Delta H$ and $w_{2}$ are shown in figure 1 . For the pure substance two regions of motional

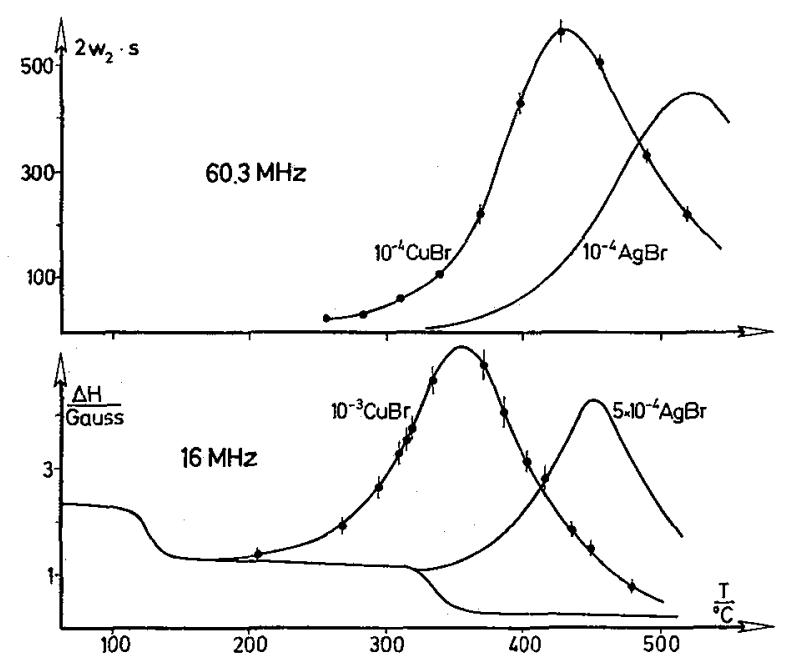

FIG. 1. - Linewidth $\Delta H$ and longitudinal relaxation rate constant $w_{2}$ of ${ }^{81} \mathrm{Br}$ in $\mathrm{LiBr}$ with additions of $\mathrm{CuBr}$ and $\mathrm{AgBr}$. Experimental points are shown only for $\mathrm{LiBr}$ doped with $\mathrm{CuBr}$.

narrowing of the linewidth can be observed (lower part of Fig. 1). The first decrease at $120^{\circ} \mathrm{C}$ is caused by the motion of $\mathrm{Li}^{+}$-ions. The reason for the second decrease at $330^{\circ} \mathrm{C}$ is the motion of $\mathrm{Br}^{-}$-ions. It can be concluded that $v\left(\mathrm{Br}^{-}\right)$is of the order of $10^{4} \mathrm{~s}^{-1}$ at $330^{\circ} \mathrm{C}$.
If $\mathrm{CuBr}$ or $\mathrm{AgBr}$ is added, a pronounced maximum in the temperature dependence of the linewidth shows up at 350 or $450^{\circ} \mathrm{C}$ respectively. This maximum is due to transversal relaxation by quadrupole interaction between the diffusing foreign cations and the ${ }^{81} \mathrm{Br}$ nuclei. The jump frequency $v\left(\mathrm{Br}^{-}\right)$in equation (1) can be neglected in this case. In the upper part of figure 1 results for the contribution of diffusion to longitudinal relaxation are shown $\left(w_{2}\right)$. The concentrations of the foreign ions are considerably lower than in the linewidth measurements. The maxima for $w_{2}$ appear at a somewhat higher temperature than in the lower part of figure 1 . The reason is mainly that the Larmor-frequency used in the pulse experiments is higher by a factor of 3.75 than in the linewidth determinations.

The mean jump frequencies of $\mathrm{Cu}^{+}$and $\mathrm{Ag}^{+}$derived from the measurements are

$$
v\left(\mathrm{Cu}^{+}\right)=1.5 \times 10^{16} \exp (-1.0 \mathrm{eV} / k T) \mathrm{s}^{-1}
$$

and

$$
v\left(\mathrm{Ag}^{+}\right)=2 \times 10^{15} \exp (-1.0 \mathrm{eV} / k T) \mathrm{s}^{-1} .
$$

These frequencies are valid for temperatures above $350^{\circ} \mathrm{C}$. From determinations of longitudinal relaxation rates of ${ }^{7} \mathrm{Li}$ in the same substance [14] it can be concluded that $\mathrm{Cu}^{+}$and $\mathrm{Ag}^{+}$are both incorporated substitutionally in $\mathrm{LiBr}$ and that $\mathrm{Cu}^{+}$diffuses considerably faster than $\mathrm{Li}^{+}$whereas $\mathrm{Ag}^{+}$has approximately the same jump frequency as $\mathrm{Li}^{+}$at $450{ }^{\circ} \mathrm{C}$. For the corresponding diffusion coefficients of $\mathrm{Cu}^{+}$ and $\mathrm{Ag}^{+}$in $\mathrm{LiBr}$ the preexponential factors $\mathrm{D}_{0}$ are $D_{0}\left(\mathrm{Cu}^{+}\right)=8$ and $D_{0}\left(\mathrm{Ag}^{+}\right)=1 \mathrm{~cm}^{2} \mathrm{~s}^{-1}$. These values have been calculated under the assumption of diffusion by cation vacancies in nearest neighbour position.

4. Diffusion of $\mathrm{K}^{+}, \mathbf{R b}^{+}, \mathrm{Cs}^{+}$and $\mathrm{Ag}^{+}$in $\mathrm{TlBr}$. Results for the temperature dependence of the ${ }^{81} \mathrm{Br}$ linewidth in $\mathrm{TlBr}$ are shown in figure 2 . For the pure material (Serva; 99.998\%) motional narrowing occurs between 100 and $200{ }^{\circ} \mathrm{C}$. Additions of $\mathrm{K}^{+}$,

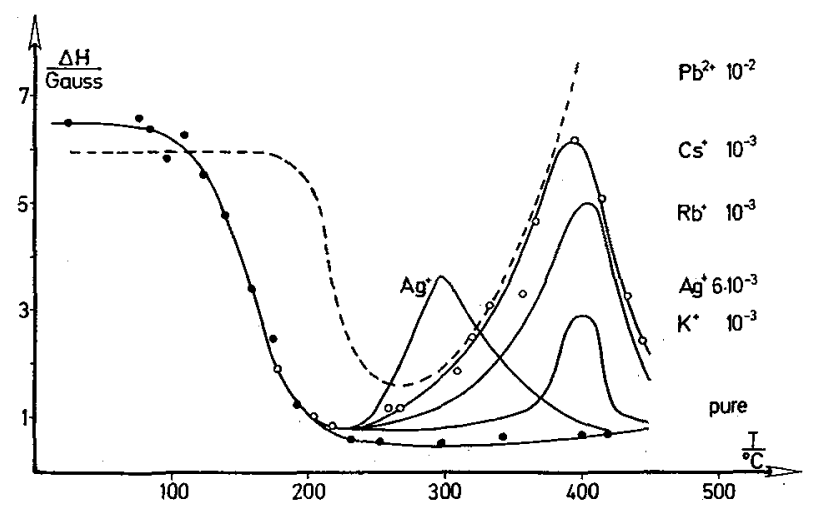

FIG. 2. - Linewidin $\Delta H$ of $81 \mathrm{Br}$ in $\mathrm{TlBr}$ with additions of foreign cations $\left(v_{\mathrm{L}}=16 \mathrm{MHz}\right)$. Experimental points are shown only for pure $\mathrm{TlBr}$ and $\mathrm{TlBr}$ doped with $\mathrm{CsBr}$. 
$\mathrm{Rb}^{+}, \mathrm{Cs}^{+}$and $\mathrm{Ag}^{+}$do not change the motional narrowing but in each case a maximum of transversal relaxation is observed. (For $\mathrm{Li}^{+}$and $\mathrm{Na}^{+}$the solubility at $400{ }^{\circ} \mathrm{C}$ seems to be smaller than $10^{-3}$; for $\mathrm{Cu}^{+}$no relaxation maximum could be obtained.) For $\mathrm{K}^{+}$, $\mathrm{Rb}^{+}$and $\mathrm{Cs}^{+}$the temperatures $T^{*}$ at the relaxation peaks coincide $\left(T^{*}=400{ }^{\circ} \mathrm{C}\right)$; for $\mathrm{Ag}^{+}$the corresponding temperature is $T^{*}=300^{\circ} \mathrm{C}$.

The observed relaxation maxima are again due to quadrupole relaxation by the relative diffusive motion between the foreign cations (which produce the electric field gradient) and the ${ }^{81} \mathrm{Br}$-nuclei. For $\mathrm{TlBr}$, however, the jump frequency of the $\mathrm{Br}^{-}$-ions cannot be neglected in comparison to that of the foreign ions as in the case of $\mathrm{LiBr}$. From earlier measurements of electrical conductivity, tranference number and Tl-self-diffusion $[21,22]$ it can be concluded, that the anions are much more mobile than the cations in $\mathrm{TlBr}$. (For the anions and cations in $\mathrm{TlCl}$ the ratio between the mobilities has been quantitatively determined [23], at $400^{\circ} \mathrm{C}$ this ratio is 15$)$. The jump frequency $v(\mathrm{D}) \equiv v\left(\mathrm{M}^{+}\right)$of the foreign cations can be evaluated from the measured correlation time $\tau$ only if $v\left(\mathrm{Br}^{-}\right)$can be obtained separately. In the present case $v\left(\mathrm{Br}^{-}\right)$can be calculated from measurements of ionjc conductivity [21] and Tl tracer-diffusion [22]. The Tl-ions at this temperature contribute only $10 \%$ to the total conductivity. The result is

$v\left(\mathrm{Br}^{-}\right)=(7.8 \pm 2) 10^{7}$ and $v\left(\mathrm{Tl}^{+}\right)=1 \times 10^{7} \mathrm{~s}^{-1}$

for a jump process via vacancies in nearest neighbour positions. For the foreign ions $\mathrm{K}^{+}, \mathrm{Rb}^{+}$and $\mathrm{Cs}^{+}$the jump frequencies are therefore

$$
v\left(\mathrm{M}^{+}\right)=(4.5 \pm 2) 10^{7} \cdot \mathrm{s}^{-1} \text { at } 400^{\circ} \mathrm{C} .
$$

In the case of $\mathrm{Ag}^{+}, v\left(\mathrm{Br}^{-}\right)$can be neglected in comparison to $1 / \tau$ and one directly obtains

$$
v\left(\mathrm{Ag}^{+}\right)=12 \times 10^{7} \mathrm{~s}^{-1} \text { at } 300^{\circ} \mathrm{C} \text {. }
$$

The conclusion is, that the diffusion of $\mathrm{K}^{+}, \mathrm{Rb}^{+}$and $\mathrm{Cs}^{+}$in $\mathrm{TlBr}$ at $400^{\circ} \mathrm{C}$ is appreciably faster than the $\mathrm{Tl}^{+}$-diffusion but slower than the diffusion of the $\mathrm{Br}^{-}$-ions. The diffusion of $\mathrm{Ag}^{+}$, however, is at $300^{\circ} \mathrm{C}$ more than ten times faster than the anion-diffusion. In the latter case probably the diffusion mechanism is different.

Figure 2 also contains some results for TIBr doped with $\mathrm{Pb}^{2+}$. In this case motional narrowing occurs at temperatures which are about $50 \mathrm{~K}$ higher than in the pure substance. This can easily be understood by Schottky-disorder in $\mathrm{TlBr}$ : The concentration of anion-vacancies is lowered by the addition of divalent cations. At temperatures above $300^{\circ} \mathrm{C}$ the linewidth shows a steep increase. This again results from quadrupole relaxation by relative diffusive motion of $\mathrm{Pb}^{2+}$ and $\mathrm{Br}^{-}$.

5. Diffusion of copper-ions in $\mathrm{AgCl}$ and $\mathrm{AgBr}$. In $\mathrm{AgCl}$ and $\mathrm{AgBr}$ the diffusion of numerous foreign ions has been studied [see e. g. 24-25]. For $\mathrm{Cd}^{2+}$. and $\mathrm{Mn}^{2+}$-ions in $\mathrm{AgBr}$ the diffusion coefficients have been determined both by the tracer method and by nuclear magnetic relaxation via quadrupole interaction $[26,27,11,28]$. The difference at 350 $400{ }^{\circ} \mathrm{C}$ between the results of the two methods is less than $20 \%$ in both cases (calculation of $D$ according to $D\left(\mathrm{M}^{2+}\right)=l^{2} /(6 \tau)$; with $l$ : distance between nearest neighbours in the cation lattice). Among all foreign ions investigated by the tracer method $\mathrm{Cu}^{+}$shows the highest diffusion coefficient. The numerical value at $200^{\circ} \mathrm{C}$ in $\mathrm{AgCl}$ is

$$
D^{\operatorname{tr}}\left(\mathrm{Cu}^{+}\right)=5 \times 10^{-7} \mathrm{~cm}^{2} \mathrm{~s}^{-1}
$$

$\left(D^{\operatorname{tr}}\left(\mathrm{Ag}^{+}\right)\right.$at the same temperature is $5.5 \times$ $10^{-10} \mathrm{~cm}^{2} \mathrm{~s}^{-1}$ only [29]).

Results for our ${ }^{35} \mathrm{Cl} \mathrm{nmr-relaxation} \mathrm{measurements}$ in $\mathrm{AgCl}$ are shown in figure 3. When $\mathrm{Cu}^{+}$is added,

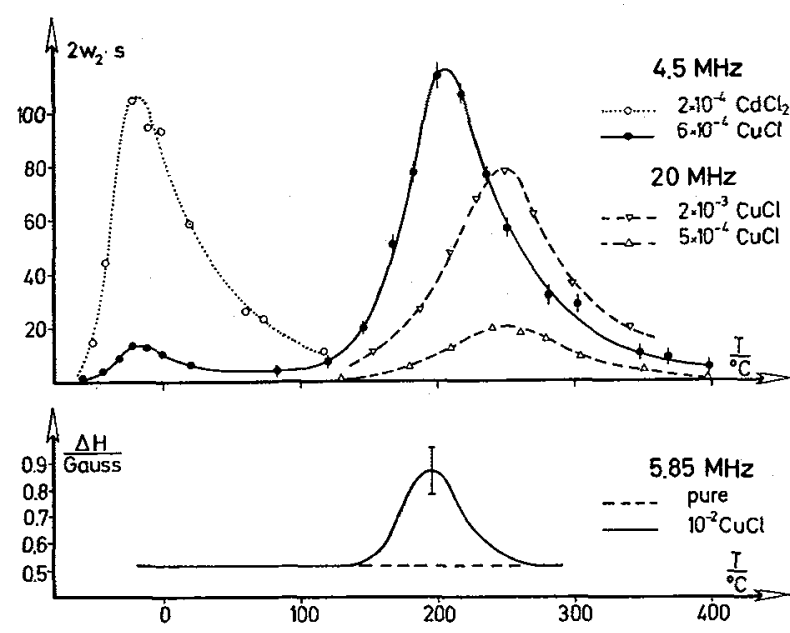

FIg. 3. - Linewidth $\Delta H$ and longitudinal relaxation rate constant $w_{2}$ of ${ }^{35} \mathrm{Cl}$ in $\mathrm{AgCl}$ with additions of $\mathrm{CuCl}$ and $\mathrm{CdCl}_{2}$.

a maximum in the linewidth is observed at $200^{\circ} \mathrm{C}$ approximately. The signal to noise ratio in these cwexperiments is rather poor. Much better is the precision in the determination of the longitudinal relaxation $\left(w_{2}\right)$ from measurements with doped and pure samples. In the upper part of figure $3 w_{2}$ is plotted against temperature. For a sample $\mathrm{AgCl}+6 \times 10^{-4} \mathrm{CuCl}$ and a Larmor frequency of $v_{L}=4.5 \times 10^{6} \mathrm{~s}^{-1}$ the main relaxation maximum is observed at $205^{\circ} \mathrm{C}$ (full curve in figure 3). A second maximum, which is much weaker, shows up at $-20^{\circ} \mathrm{C}$ with the same sample.

For the main relaxation maximum figure 3 shows some results for the influence of Larmor-frequency $v_{L}$ and concentration of the added ion $x_{\mathrm{d}}$ (dashed curves). The proportionality of the peak height $w_{2}^{*}$ to $x_{\mathrm{d}} / \omega_{\mathrm{L}}$ is observed as expected from equation (5). In addition the peak temperature $T^{*}$ is shifted with frequency 
as expected from (4). Calculation of a jump frequency $v(D)$ with the aid of equations (1)-(5) leads to

$$
v(\mathrm{D})=1.4 \times 10^{15} \exp (-0.7 \mathrm{eV} / k T) \mathrm{s}^{-1} .
$$

With a mean jump length $l=d / \sqrt{2}(d$ : lattice constant) at $205^{\circ} \mathrm{C}$ a diffusion coefficient of

$$
D^{\mathrm{nmr}}(\mathrm{Cu})=5 \times 10^{-9} \mathrm{~cm}^{2} \mathrm{~s}^{-1}
$$

results. Using ${ }^{64} \mathrm{Cu}$ as tracer Süptitz [30] obtained at the same temperature $D^{\operatorname{tr}}(\mathrm{Cu})=5.6 \times 10^{-7} \mathrm{~cm}^{2} \mathrm{~s}^{-1}$ with an activation energy of $0.4 \mathrm{eV}$. The large ratio $D^{\mathrm{tr}}\left(\mathrm{Cu}^{+}\right) / D^{\mathrm{nmr}}\left(\mathrm{Cu}^{+}\right) \approx 100$ at $205^{\circ} \mathrm{C}$ and the difference in activation energy can only be accounted for if in both cases a different diffusion mechanism is decisive (with $l=d / 2$ as for interstitial diffusion the factor is still 50). This has already been discussed in connection with the diffusion of $\mathrm{Cu}^{+}$in $\mathrm{AgBr}[10$, $11,31]$. In $\mathrm{AgBr}$ the corresponding ratio $D^{\mathrm{tr}} / D^{\mathrm{nmr}}$ is approximately 10 , the activation energy from the nmr data, however, is only $10 \%$ larger than for tracer diffusion. What is most probably observed in nmr-relaxation is the mean frequency with which a $\mathrm{Cu}^{+}$-ion jumps from normal lattice site to a neighbouring interstitial position. The complex of the interstitial ion and the vacancy formed by this process contributes to tracer diffusion since the defect pair can make a considerable number of jumps before recombination takes place. On the other hand dissociation of the complex may occur and fast diffusion of the free interstitial $\mathrm{Cu}^{+}$-ion can be decisive for tracer diffusion. Süptitz [30] has concluded from the concentration dependence of $D^{\operatorname{tr}}\left(\mathrm{Cu}^{+}\right)$that this is the case in $\mathrm{AgCl}$ and $\mathrm{AgBr}$. Conductivity measurements for $\mathrm{AgCl}$ with increasing concentration of $\mathrm{CuCl}$ lead to the same conclusion [32].

The second relaxation maximum at $-20^{\circ} \mathrm{C}$ originates from the diffusion of cation vacancies. This can be seen by comparison with results for longitudinal relaxation in $\mathrm{AgCl}$ with small additions of $\mathrm{CdCl}_{2}$ (dotted curve in Fig. 3). It also can be concluded by analogy from $\mathrm{nmr}$-measurements on $\mathrm{AgBr}$ doped with $\mathrm{CdBr}_{2}[2,10,11]$. The calculation of the jump frequency of cation vacancies $\mathrm{v}(\mathrm{V})$ in $\mathrm{AgCl}$ from conductivity data [33] leads to $v(\mathrm{~V})=10^{8} \mathrm{~s}^{-1}$ at $-20^{\circ} \mathrm{C}$ which is in reasonable agreement with $1 / \tau^{*}=5.6 \times 10^{7} \mathrm{~s}^{-1}$ (for $v_{\mathrm{L}}=4.5 \times 10^{6} \mathrm{~s}^{-1}$ ). Thus it follows from the observation of the second maximum at $-20^{\circ} \mathrm{C}$ that some vacancies are formed when $\mathrm{CuCl}$ is added to $\mathrm{AgCl}$. Consequently some $\mathrm{Cu}^{+}$-ions are incorporated at interstitial positions. This has also been found with $\mathrm{AgBr}$ [4] and has been concluded from conductivity data and tracer results $[34,32,30]$. The difference in $w_{2}^{*}$ at the second maximum for $\mathrm{Cu}^{+}-$and $\mathrm{Cd}^{2+}$-addition shows that the fraction of $\mathrm{Cu}^{+}$on interstitial position is small.

In $\mathrm{AgBr}$ containing $10^{-2} \mathrm{CuBr}$ we have tried to produce some $\mathrm{Cu}^{2+}$ by treatment with gaseous bromine. The sample was exposed to a given partial pressure $P\left(\mathrm{Br}_{2}\right)$ at a temperature slightly above the melting point and sealed afterwards. Results for the ${ }^{81} \mathrm{Br}$-linewidth as function of temperature are shown in figure 4. Without bromine the $\mathrm{Cu}^{+}$-maximum is

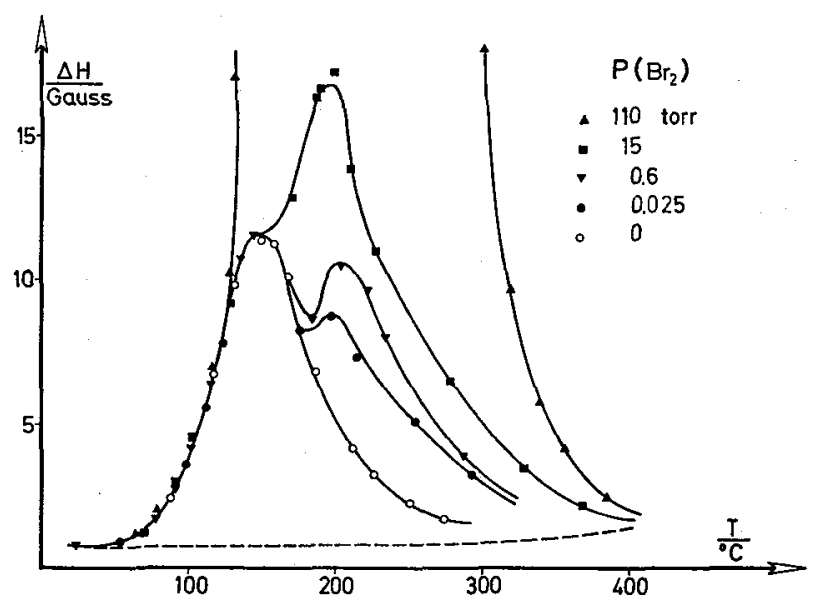

FIG. 4. - Linewidth $\Delta H$ of ${ }^{81} \mathrm{Br}$ in $\mathrm{AgBr}+10^{-2} \mathrm{CuBr}$ treated with bromine.

observed in this case at $145^{\circ} \mathrm{C}$ for $v_{\mathrm{L}}=16 \times 10^{6} \mathrm{~s}^{-1}$. Under the influence of bromine a second relaxation maximum develops. This maximum at $200^{\circ} \mathrm{C}$ is with high probability due to diffusion of $\mathrm{Cu}^{2+}$-ions. Since the peak temperature $T^{*}$ for $\mathrm{Cu}^{2+}$ is higher than for $\mathrm{Cu}^{+}$, the jump frequency of $\mathrm{Cu}^{2+}$ at a given temperature is lower than the frequency of the $\mathrm{Cu}^{+}$-process described above in the case of $\mathrm{AgCl}$. The height of the $\mathrm{Cu}^{2+}$-maximum is obviously much greater than in the case of $\mathrm{Cu}^{+}$for a given concentration. The $\mathrm{Cu}^{2+}$. concentration is unknown. It is certainly small since the concentration of $\mathrm{Cu}^{+}$is not decreased to a considerable extent by the formation of $\mathrm{Cu}^{2+}$. The dependence of the $\mathrm{Cu}^{2+}$-concentration on $P\left(\mathrm{Br}_{2}\right)$ can roughly be estimated : it is proportional to $P^{1 / n}$ with $n=4 \pm 1$ [35].

6. Conclusion. - The examples show that with the method described not only the diffusion of atomic defects with an excess charge (aliovalent ions, interstitials, vacancies) can be investigated. Small concentrations of substitutionally incorporated foreign ions with the same valency as the ions of the matrix crystal obviously give rise to an electric field gradient which is so large that the nuclear magnetic relaxation rate is mainly determined by diffusion and quadrupole interaction in the appropriate temperature range. This considerably extends the applicability of the method. It offers the opportunity to investigate and compare the diffusion of a wide variety of foreign ions in the same crystal. No single crystals are necessary for the measurements. The formulae given in section 2 apply to crystal powders only.

If more than one defect is produced by one impurity, 
these defects may be separately detected if the difference in their jump frequency is large enough. The same holds true for the case of doping with two foreign ions. In certain cases jump processes may be detected, which do not show up in tracer diffusion and ionic conductivity.

Among the elements for which (as main crystal constituents) such relaxation measurements can be made (in natural isotopic composition) are $\mathrm{Cl}, \mathrm{Br}, \mathrm{I}$, $\mathrm{Li}, \mathrm{Na}, \mathrm{Rb}, \mathrm{Cs}, \mathrm{Be}, \mathrm{Al}$ and $\mathrm{Cu}$. The strength of quadrupole interaction is, however, quite different in different cases. For a hypothetical given defect at given concentration for instance ${ }^{81} \mathrm{Br}$ is more than 1000 times more sensitive than ${ }^{23} \mathrm{Na}$ for quadrupole relaxation. Thus for ${ }^{81} \mathrm{Br}$ very small additions and transversal relaxation are favorite whereas with ${ }^{23} \mathrm{Na}$ a higher concentration range and longitudinal relaxation may be preferable.

Difficulties in the interpretation of the measurements can arise from a number of reasons. Among these are contributions of other interactions to relaxation, influences of static quadrupole interactions other than those mentioned in section 2, contribution of several jump processes to relaxation at the same temperature, association between defects, difficulties of theory (especially for $I>3 / 2$ ). If a relaxation maximum is obtained with addition of an impurity, however, some valuable information is obtained in almost any case for the temperature of the relaxation maximum and comparison with other ions is possible.

\section{References}

[1] Cohen, M. H. and ReIF, F., Proceedings of the Conference on Defects in Crystalline Solids, Physical Society, London 1955, p. 44.

[2] ReIf, F., Phys. Rev. 100 (1955) 1597.

[3] Conen, M. H. and Reif, F., Solid State Physics, Vol. 5, ed. F. Seitz and D. Turnbull (Academic Press, New York) 1957, p. 322.

[4] Becker, K. D., HamanN, H., Kozubek, N. and RichteRING, H., Ber. Bunsenges. Phys. Chem. 79 (1975) 1124.

[5] Allen, R. R. and Weber, M. J., J. Chem. Phys. 38 (1963) 2970.

[6] Linga Murty, K. and Ruoff, A. L., Phys. Rev. B 1 (1970) 114.

[7] Mahendroo, P. P. and Nolle, A. W., Phys. Rev. 126 (1962) 125

[8] SATOH, M., J. Phys. Soc. Japan 20 (1965) 1008.

[9] Berg, G., FröHlich, F. and PoHL, D., Cryst. Lattice Defects 3 (1973) 213.

[10] SeIfERT, G., Z. Phys. 161 (1961) 132.

[11] Becker, K. D. and Richtering, H., Ber. Bunsenges. Phys. Chem. 78 (1974) 461.

[12] Kluge, J., Phys. Status Solidi 13 (1966) 401.

[13] Hubbard, P.S., J. Chem. Phys. 53 (1970) 985.

[14] Becker, K. D., HamanN, H., Reininghaus, J. and RichteRING, H., Ber. Bunsenges. Phys. Chem., to be published.

[15] Andersson, L.-O., Arkiv Fysik 35 (1968) 85.

[16] Eisenstadt, M. and Redfield, A. G., Phys. Rev. 132 (1963) 635.

[17] Wolf, D., Z. Naturforsch. 26 a (1971) 1816.

[18] LeClatre, A. D., Physical Chemistry, Advanced Treatise, Vol. X., ed. W. Jost (Academic Press, New York) 1970 , p. 261.
[19] Torrey, H. C., Phys. Rev. 92 (1953) 962.

[20] Wolf, D., J. Magnetic Resonance 17 (1975) 1.

[21] Herrmann, P., Z. Phys. Chem. Leipzig 227 (1964) 338.

[22] Kurihara, S., Fuexi, K. and Mukaibo, T., J. Solid State Chem. 8 (1973) 229.

[23] Friauf, R. J., Atomic Transport in Solids and Liquids, ed. Lodding, A. and Lagerwall, T. (Verl. Z. Naturforschg. Tübingen) 1971, p. 270.

[24] Süptirz, P. and Teltow, J., Phys. Status Solidi 23 (1967) 9.

[25] KRöger, F. A., The Chemistry of Imperfect Crystals, 2nd edition, Vol. 2 (North Holland Publ. Comp. Amsterdam) 1974, p. 500.

[26] Hanlon, J. E., J. Chem. Phys. 32 (1960) 1492.

[27] Süptitz, P. and WeidmanN, R., Phys. Status Solidi 27 (1968) 631.

[28] ReINinghaus, J., diploma thesis Ruhr-Universitat Bochum (1976).

[29] Reade, R. F. and Martin, D. S., J. Appl. Phys. 31 (1960) 1965.

[30] Süptitz, P., Phys. Status Solidi 7 (1964) 653, 667.

[31] Süptitz, P., Phys. Status Solidi 13 (1966) K 135.

[32] Abrink, H. C. and Martin, D. S., J. Phys. \& Chem. Solids 33 (1972) 913.

[33] MÜller, P., Phys. Status Solidi 12 (1965) 775.

[34] Teltow, J., Z. Phys. Chem. 195 (1950) 197.

[35] BeCKer, K. D., Ber. Bunsenges. Phys. Chem. 80 (1976) 1243.

[36] Becker, K. D., Herzog, G. W., KanNe, D., RichteRING, H. and STAdler, E., Ber. Bunsenges. Phys. Chem. 74 (1970) 527.

\section{DISCUSSION}

R. J. Friauf. - How does it happen in $\mathrm{AgCl}$ with $\mathrm{Cu}$ that you do not see the jumps of the interstitial copper ions?

H. RICHTERING. - For interstitial $\mathrm{Ca}^{+}$-ions the main contribution to relaxation is to be expected at temperatures considerably below $200{ }^{\circ} \mathrm{C}$. It is possible that this contribution is already contained in the solid curve in figure 3 and simply cannot be resolved. It is also possible that this contribution occurs at even lower temperatures than $-60^{\circ} \mathrm{C}$. Alternatively, the second maximum at $-20^{\circ} \mathrm{C}$ may be due to jumps of a vacancy in the complex $\left(\mathrm{Cu}_{\mathrm{i}}^{\cdot} \mathrm{V}_{\mathrm{Ag}}^{\prime}\right)$ and the concentrations of free vacancies and interstitial $\mathrm{Cu}^{+}$-jons are too small to be detected. 